\title{
Prevalence and Molecular Profile of Breast Carcinoma Using Immunohistochemistry Markers in Mexican Women
}

\author{
Andres Macari ${ }^{\mathrm{a}}$, Pamela Soberanis-Pina ${ }^{\mathrm{b}}$, Edgar Varela-Santoyo ${ }^{\mathrm{b}}$, Marco Antonio Valle-Sanchez ${ }^{\mathrm{b}}$, \\ Jorge Luis Leal-Hidalgo ${ }^{\mathrm{b}}$, Valeria M. Torres-Guillen ${ }^{\mathrm{c}}$, Daniel Motola-Kuba ${ }^{\mathrm{b}}$, \\ Jose Manuel Ruiz-Morales ${ }^{\mathrm{b}}$, Rita Dorantes-Heredia ${ }^{\mathrm{a}, \mathrm{d}}$
}

\begin{abstract}
Background: In Mexico, breast cancer is the leading cause of death by malignant tumors in women aged 20 and older. The World Health Organization estimates that $69 \%$ of deaths caused by breast cancer occur in developing countries. Little is known about the prevalence of breast carcinoma in Mexico and its molecular subclassification.

Methods: This retrospective cross-sectional study included patients who underwent a mastectomy (single, radical or lumpectomy) or a breast tumor biopsy (core-needle or excisional) from January 2002 to December 2018. The primary purpose of the study was to determine the prevalence and molecular profile of breast in comprehensive cancer center in Mexico and compare our results with those published in the US. This study was approved by our scientific and bioethical committee.

Results: The final analysis included 379 patients. The youngest patient was 23 years old and the oldest patient was 89 ; the mean age at diagnosis was 54.63 years. Patients of 40 years old or younger accounted for 48 of the cases (12.66\%) and those older than 40 accounted for 331 of the cases $(87.33 \%)$. The molecular subclassification showed luminal A subtype in 139 cases (36.67\%), luminal B subtype in 143 cases $(37.73 \%)$, human epidermal growth factor receptor 2-positive carcinomas in 32 cases $(8.44 \%)$ and triple-negative carcinomas in 65 cases $(17.15 \%)$. Diabetes mellitus was present in 43 patients $(11.34 \%)$, hypertension in 78 patients $(20.58 \%)$, obesity in 82 patients $(21.63 \%)$ and 66 patients reported being treated with exogenous hormone therapy $(17.41 \%)$.
\end{abstract}

Manuscript submitted May 20, 2021, accepted June 24, 2021

Published online July 10, 2021

${ }^{a}$ Anatomic Pathology Research Unit, Medica Sur Hospital and Clinical Foundation, Mexico City, Mexico

${ }^{b}$ Medical Oncology Research Unit, Medica Sur Hospital and Clinical Foundation, Mexico City, Mexico

'Universidad de las Americas Puebla, San Andres Cholula, Puebla, Mexico ${ }^{\mathrm{d} C}$ Corresponding Author: Rita Dorantes-Heredia, Medical Oncology Research Unit, Medica Sur Hospital and Clinical Foundation, Puente de Piedra 150, Col. Toriello Guerra, Tlalpan 14050, Mexico City, Mexico.

Email: ritadorantesh@gmail.com

doi: https://doi.org/10.14740/wjon1392
Conclusions: Breast carcinoma occurs at an earlier age in Mexican women compared to women in the US. Hormone-positive tumors were found to be more prevalent in older patients, while high-grade tumors were more frequently identified in younger patients.

Keywords: Breast cancer; Neoplasm; Obesity; Pathogenesis

\section{Introduction}

Breast carcinoma is the most frequent type of cancer in women and the second most frequent in the world, according to data from Globocan [1]. The World Health Organization (WHO) estimates 1.38 million new cases and 458,000 deaths for 2020 [2]. The National Institute of Statistics and Geography (INEGI) states that breast cancer is the leading cause of death by malignant tumors in Mexican women of 20 years of age or older, and the WHO estimates that $69 \%$ of deaths caused by breast carcinoma occur in developing countries [3]. Breast cancer was first molecularly subclassified using DNA microarrays and variation in gene expression allowed the breast carcinoma to be subclassified into four groups: estrogen receptor (ER)+/luminal-like, basal-like, Erb-B2+ and normal breast [4]. The variation between the molecular profile of each tumor and a patient's clinical outcome was later established $[5,6]$. The molecular subclassification was later performed using immunohistochemistry markers, subclassifying the even further into: luminal A, luminal $\mathrm{B}$, human epidermal growth factor receptor 2 (HER2)-positive and triple-negative, with the same statistical significance and clinical outcomes [7,8], compared with studies done with DNA microarrays. According to the WHO, in 2018, there were 27,283 new cases of breast cancer in Mexico, representing 26\% of all types of cancer [1]. There is evidence that Mexican women have a higher prevalence of triple-negative breast carcinomas and an earlier age of onset than is typical in other countries [9]. Little is known about the prevalence and molecular subclassification of breast carcinoma in Mexico, and it is important to determine such prevalence and identify other co-factors (such as age) to improve medical treatment and prognostic values; therefore, we conducted a retrospective analysis. 

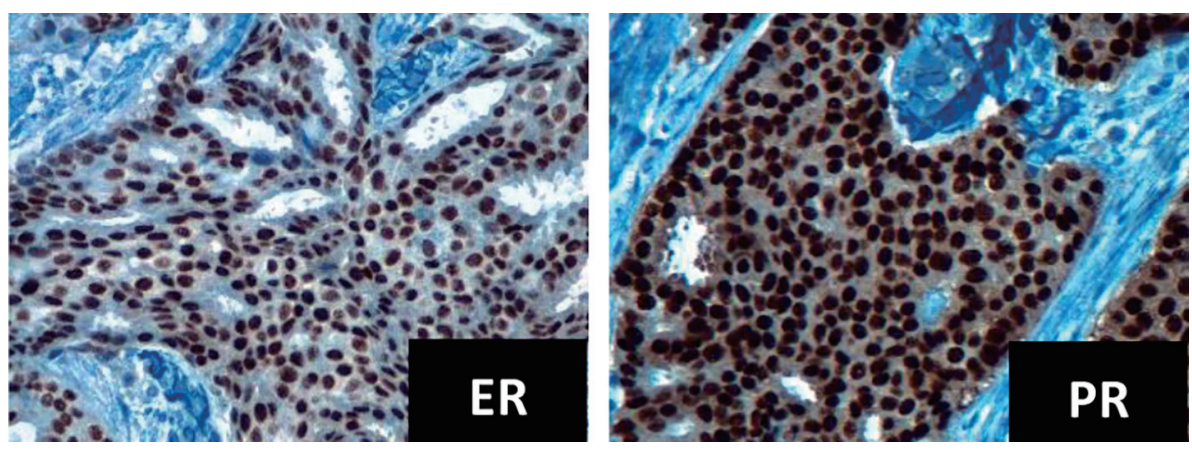

Figure 1. Immunohistochemistry for ER and PR positives, intensity +++ in $95 \%$ tumor cells ( $\times 40$ field). ER: estrogen receptor; PR: progesterone receptor.

\section{Materials and Methods}

\section{Patients}

Patients who underwent a mastectomy (single, radical or lumpectomy) or a breast tumor biopsy (core-needle or excisional) from January 2002 to December 2018 at our institution were eligible for inclusion in this study. Cases were identified and reviewed retrospectively under the microscope and subclassified using immunohistochemistry markers (ER, progesterone receptor (PR), HER2/Neu and Ki-67). A complete medical history was obtained, including the patient's personal history of diabetes mellitus, hypertension, obesity and exogenous hormone therapy. This study was approved by the institutional Scientific and Bioethical committee (CONBIOETICA09-CEI-018 2016729 Id: 2020-EXT-475).

\section{Outcomes}

The primary goal of the study was to determine the prevalence and molecular profile of breast carcinoma (luminal A, luminal B, HER2-positive and triple-negative) in patients of 40 years of age and younger, as well as patients of above 40 years of age, and determine the association of breast carcinoma with other factors, such as obesity, diabetes mellitus and hypertension.

\section{Statistical analysis}

Continuous variables were grouped as arithmetic means, medians and standard deviations. Categorical variables were exposed as proportions with $95 \%$ confidence intervals $(95 \%$ CIs). Percentages were calculated and shown in simple graphs. The Chi-square test was employed to calculate the statistical significance between categorical variables. Results with borderline and statistical significance $(\mathrm{P}<0.1$ and $\mathrm{P}<0.05$, respectively) were included in the logistic regression analysis.

Disease-free interval stay was analyzed using the KaplanMeier method, and subgroups were compared with the Breslow test. Statistical significance was determined with a $\mathrm{P} \leq$
0.05 in a two-sided test. All statistical tests were performed with SPSS software (version 25.0; SPSS, Inc., Chicago, IL).

\section{Results}

\section{Patients}

Between January 2002 and December 2018, 379 patients who had a mastectomy (single, radical or lumpectomy) or a breast tumor biopsy (core-needle or excisional) fulfilled protocol criteria and were included for the final analysis. The youngest patient was 23 years old, while the oldest patient was 89 years. The mean age at diagnosis was 54.63 years. Patients of 40 years or younger accounted for 48 of the cases $(12.66 \%)$, while those older than 40 years accounted for 331 of the cases $(87.33 \%)$.

\section{Outcomes}

Of the 379 cases, the most common subtype was hormonal receptor-positive carcinoma with 282 cases (74.40\%), of which 139 cases $(36.67 \%)$ were luminal $\mathrm{A}$ and 143 cases $(37.73 \%)$

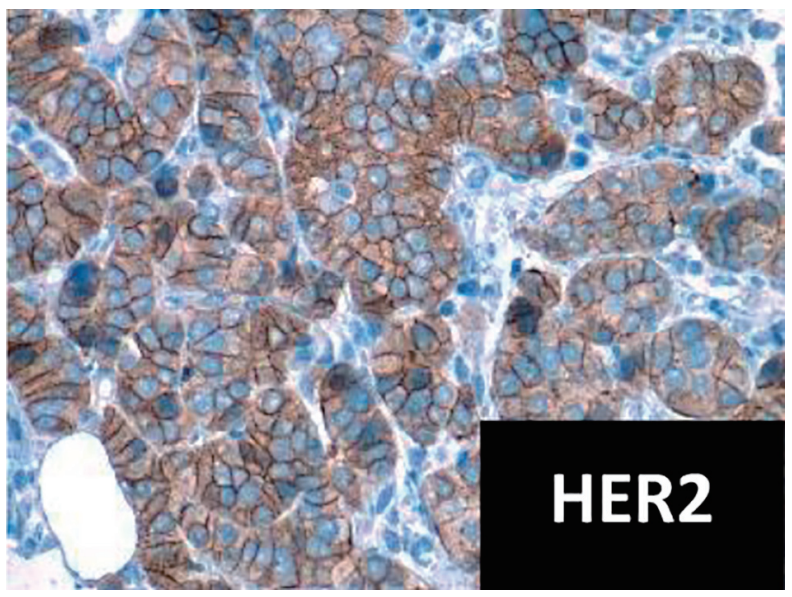

Figure 2. Immunohistochemistry for HER2 positive ( $\times 40$ field). HER2: human epidermal growth factor receptor 2. 
Table 1. Detailed Characteristics of Each Molecular Subtype

\begin{tabular}{|c|c|c|c|c|c|c|c|}
\hline $\begin{array}{l}\text { Molecular } \\
\text { subtype }\end{array}$ & $\begin{array}{l}\text { All patients } \\
(n=379)\end{array}$ & $\begin{array}{l}\text { Patients aged } \leq \\
40 \text { years }(n=48)\end{array}$ & $\begin{array}{l}\text { Patients aged }>40 \\
\text { years }(n=331)\end{array}$ & $\begin{array}{l}\text { Carcinoma } \\
\text { NST }(n=269)\end{array}$ & $\begin{array}{l}\text { Lobular } \\
\text { carcinoma } \\
(\mathbf{n}=\mathbf{5 1})\end{array}$ & $\begin{array}{l}\text { Medullary } \\
\text { carcinoma } \\
(n=9)\end{array}$ & $\begin{array}{l}\text { Mucinous } \\
\text { carcinoma } \\
(\mathrm{n}=5)\end{array}$ \\
\hline Luminal $\mathrm{A}^{\mathrm{a}}$ & $139(36.67 \%)$ & $7(14.58 \%)$ & $132(39.87 \%)$ & $81(30 \%)$ & $27(53 \%)$ & $0(0 \%)$ & $5(100 \%)$ \\
\hline Luminal B ${ }^{b}$ & $143(37.73 \%)$ & $26(54.16 \%)$ & $117(35.34 \%)$ & $110(41 \%)$ & $17(33 \%)$ & $0(0 \%)$ & $0(0 \%)$ \\
\hline HER2-positive ${ }^{c}$ & $32(8.44 \%)$ & $3(6.25 \%)$ & $29(8.76 \%)$ & $31(12 \%)$ & $0(0 \%)$ & $0(0 \%)$ & $0(0 \%)$ \\
\hline Triple-negative $^{\mathrm{d}}$ & $65(17.15 \%)$ & $12(25 \%)$ & $53(16.01 \%)$ & $47(17 \%)$ & $7(14 \%)$ & $9(100 \%)$ & $0(0 \%)$ \\
\hline
\end{tabular}

aLuminal A: ER or PR+, HER2-, and Ki-67 low (< 14\%). bLuminal B: ER or PR+, HER2-/+, and Ki-67 (HER2- > 14\%, HER2+ any \%). cHER2-positive: ER-, PR-, HER2+ (at least $>10 \%$ of tumor cells complete membrane) and Ki-67 low/high. ${ }^{d}$ Triple-negative/basal-like: ER-, PR-, HER2-, Ki-67 low/ high. ER: estrogen receptor; HER2: human epidermal growth factor receptor 2; PR: progesterone receptor; NST: no special type.

were luminal B (Fig. 1). HER2-positive carcinomas (Fig. 2) accounted for 32 of all the cases $(8.44 \%)$ and triple-negative tumors made 65 of the total cases $(17.15 \%)$. The most frequent comorbidities were obesity with 82 cases $(21.63 \%)$, followed by hypertension with 78 cases $(20.58 \%)$ and diabetes mellitus with 43 cases $(11.34 \%)$. Moreover, 66 patients $(17.41 \%)$ had a history of exogenous hormone therapy such as hormonal contraceptives or postmenopausal hormone therapy (Tables 1 and 2).

Patients who were 40 years of age or younger at the time of diagnosis represented 48 cases, of which seven cases were classified as luminal A (14.58\%), 26 cases were classified as luminal B (54.16\%), three cases were HER2-positive $(6.25 \%)$ and 12 cases were regarded as triple-negative (25\%). The most common comorbidity was diabetes mellitus in two patients $(4.16 \%)$ followed by one case of hypertension $(2.08 \%)$ and one case of obesity $(2.08 \%)$. Finally, five patients $(10.41 \%)$ had a history of exogenous hormone therapy.

Patients who were over 40 years of age at the time of diagnosis represented the majority of the population with 331 cases. Luminal A subtype was the most frequent with 132 cases $(39.87 \%)$, followed by luminal B subtype with 117 cases (35.34\%). HER2-positive tumors were found in 29 patients $(8.76 \%)$ and triple-negative tumors in 53 patients $(16.01 \%)$. The most frequent comorbidity was obesity with 81 cases $(24.27 \%)$, followed by high blood pressure with 77 cases $(23.26 \%)$ and diabetes mellitus with 41 cases $(12.38 \%)$. Exogenous hormone therapy was documented in 61 patients $(18.42 \%)$ of older than 40 years of age with breast carcinoma.

\section{Discussion}

The mean age of diagnosis of breast carcinoma in the present study was 54.63 years. This contrasts with data from the US, where the mean age of diagnosis is 61 years [10]. Our results are more in line with the findings of Lara-Medina et al [9] and Rodriguez-Cuevas et al [11], where the mean age of diagnosis of breast carcinoma in Mexican women was 50 and 53.5 years, respectively. In our study, $66.75 \%$ of women were diagnosed with breast carcinoma before turning 60 years old, which differs from women in the US, where more than half the new cases of breast cancer occur in women of 65 years of age and over [12]. We acknowledge the limitations of our study, such as being conducted in one cancer center and limited number of patients.

The prevalence of the different molecular subtypes of breast carcinoma was similar to previous findings with screening protocols, in which HER2-positive tumors represented $10-15 \%$ and triple-negative tumors $13-17 \%$ of the total of the patients analyzed. Hormone-positive tumors were more frequent in older patients, with luminal A tumors diagnosed at a mean age of 56.33 years, concurring with data from other studies. The mean age of diagnosis for luminal B tumors was 53.81 years, which also aligns with the findings of other studies in which luminal B tumors, especially ER+/PR+/HER2+, have been found more likely to occur in younger patients [13]. Triple-negative tumors represented $16.01 \%$ of the population of tumors, $80 \%$ of which displayed features of high histological grade (III). Also, in our study, 25\% of triple-negative carcinomas were diagnosed in women below 40 years of age. This confirms that young, Hispanic women are an at-risk population for triple-negative breast carcinomas [14-16]. Among the triple-negative carcinoma patients, $54.38 \%$ were alive 3 years after diagnosis and $21.05 \%$ were alive after 5 years. At the time of diagnosis, $12 \%$ of the patients were stage IV. An association was found between hormonal contraceptives and triple-negative tumors, with $12.30 \%$ of patients reporting a history of use.

Table 2. Comorbidities Found by Age Group

\begin{tabular}{llll} 
Comorbidities & $\begin{array}{l}\text { All patients } \\
(\mathbf{n = 3 7 9 )}\end{array}$ & $\begin{array}{l}\text { Patients aged } \leq \text { 40 years } \\
(\mathbf{n}=\mathbf{4 8})\end{array}$ & $\begin{array}{l}\text { Patients aged }>\text { 40 years } \\
(\mathbf{n}=\mathbf{3 3 1})\end{array}$ \\
\hline Diabetes & $43(11.34 \%)$ & $2(4.16 \%)$ & $41(12.38 \%)$ \\
Hypertension & $78(20.58 \%)$ & $1(2.08 \%)$ & $77(23.26 \%)$ \\
Obesity & $82(21.63 \%)$ & $1(2.08 \%)$ & $81(24.27 \%)$ \\
History of hormonal replacement/contraceptives & $66(17.41 \%)$ & $5(10.41 \%)$ & $61(18.42 \%)$ \\
\hline
\end{tabular}


Other studies have suggested that hormonal contraceptives are a potential risk factor, but the design of our study does not allow us to establish risk factors [17].

Of the patients with triple-negative breast carcinoma, $27.69 \%$ were either overweight or obese. However, it was only present in $7.69 \%$ of premenopausal women $(<50$ years old), which differs from the findings in other studies. Nevertheless, regarding hormone-positive tumors (luminal A/luminal B), $4.96 \%$ of premenopausal women were overweight or obese, while $18.79 \%$ of postmenopausal women ( $>50$ years old) were overweight or obese. This association is in line with the findings of other studies in which obesity in premenopausal women is not associated with increased risk and may even be a protective factor for hormone-positive breast carcinoma [18].

Exogenous hormone therapy, such as hormonal contraceptives or postmenopausal hormone therapy, is widely regarded as an associated risk factor for breast cancer [19]; however, in our study, we did not find a strong association between the two, with only $17.41 \%$ of patients having a history of exogenous hormonal therapy. Of those, only $5.80 \%$ were below 50 years of age, while $11.60 \%$ were 50 years or older, indicating that the risk is higher in postmenopausal women.

\section{Conclusion}

Breast carcinoma occurs at an earlier age for Mexican women compared to women in the US. The mean age of diagnosis for women in this study was 54.63 years. Most of the patients $(66.75 \%)$ were diagnosed before age 60 . Hormone-positive tumors were found to be more prevalent older patients, while high-grade tumors were found more frequently in young patients, with triple-negative tumors present in $25 \%$ of patients of 40 years of age or younger.

\section{Acknowledgments}

None to declare.

\section{Financial Disclosure}

None to declare.

\section{Conflict of Interest}

DMK has provided Principal Investigator of clinical trials, advisory and speaker services to AstraZeneca, Merck Sharp \& Dohme, Roche and Bristol-Myers Squibb. JMRM has provided advisory and speaker services to Ipsen, Bristol-Myers Squibb, Merck Sharp \& Dohme and Novartis and received sponsorship for travel and expenses from Bayer. RDH has provided advisory services Merck Sharp \& Dohme and received sponsorship for travel and expenses from Roche. The rest of authors declare no conflict of interest.

\section{Informed Consent}

Not applicable.

\section{Author Contributions}

All authors contributed equally to data analysis, interpretation, and writing the manuscript. Rita Dorantes Heredia, JRM, and DMK provided oversight and leadership reponsability for the research activity, planning and execution, including mentorship to the core of the team.

\section{Data Availability}

The authors declare that data supporting the findings of this study are available within the article.

\section{References}

1. Bray F, Ferlay J, Soerjomataram I, Siegel RL, Torre LA, Jemal A. Global cancer statistics 2018: GLOBOCAN estimates of incidence and mortality worldwide for 36 cancers in 185 countries. CA Cancer J Clin. 2018;68(6):394424.

2. Valle-Solis AE, Miranda-Aguirre AP, Mora-Perez J, Pineda-Juarez JA, Gallardo-Valencia LE, Santana L, Cervantes-Sanchez G, et al. [Supervivencia en cancer de mama por subtipo mediante inmunohistoquimica: Un estudio retrospectivo]. Gac Med Mex. 2019;155(Suppl 1):S50-S55.

3. Blanco S, Andisco D, Jimenez P, Luciani S. [Quality of mammography and breast cancer screening in ArgentinaQualidade da mamografia e prevencao do cancer de mama na Argentina]. Rev Panam Salud Publica. 2019;43:e63.

4. Perou CM, Sorlie T, Eisen MB, van de Rijn M, Jeffrey SS, Rees CA, Pollack JR, et al. Molecular portraits of human breast tumours. Nature. 2000;406(6797):747-752.

5. Sorlie T, Perou CM, Tibshirani R, Aas T, Geisler S, Johnsen $\mathrm{H}$, Hastie T, et al. Gene expression patterns of breast carcinomas distinguish tumor subclasses with clinical implications. Proc Natl Acad Sci U S A. 2001;98(19):1086910874.

6. Sorlie T, Tibshirani R, Parker J, Hastie T, Marron JS, Nobel A, Deng S, et al. Repeated observation of breast tumor subtypes in independent gene expression data sets. Proc Natl Acad Sci U S A. 2003;100(14):8418-8423.

7. Bhargava R, Striebel J, Beriwal S, Flickinger JC, Onisko A, Ahrendt G, Dabbs DJ. Prevalence, morphologic features and proliferation indices of breast carcinoma molecular classes using immunohistochemical surrogate markers. Int J Clin Exp Pathol. 2009;2(5):444-455.

8. Chen XL, Fan Y, Xu BH. [Clinicopathological features and prognosis of HER2-negative luminal-type breast cancer patients with early and late recurrence]. Zhonghua 
Zhong Liu Za Zhi. 2016;38(6):448-453.

9. Lara-Medina F, Perez-Sanchez V, Saavedra-Perez D, Blake-Cerda M, Arce C, Motola-Kuba D, VillarrealGarza C, et al. Triple-negative breast cancer in Hispanic patients: high prevalence, poor prognosis, and association with menopausal status, body mass index, and parity. Cancer. 2011;117(16):3658-3669.

10. Farias AJ, Ochoa CY, Toledo G, Bang SI, Hamilton AS, $\mathrm{Du}$ XL. Racial/ethnic differences in patient experiences with health care in association with earlier stage at breast cancer diagnosis: findings from the SEER-CAHPS data. Cancer Causes Control. 2020;31(1):13-23.

11. Rodriguez-Cuevas S, Guisa-Hohenstein F, Labastida-Almendaro S. First breast cancer mammography screening program in Mexico: initial results 2005-2006. Breast J. 2009;15(6):623-631.

12. Du ZL, Wang Y, Wang DY, Zhang L, Bian ZM, Deng Y, $\mathrm{Xu} \mathrm{CS}$, et al. Evaluation of a beneficial effect of adjuvant chemotherapy in patients with stage I triple-negative breast cancer: a population-based study using the SEER 18 database. Breast Cancer Res Treat. 2020;183(2):429438.

13. Parise CA, Bauer KR, Caggiano V. Variation in breast cancer subtypes with age and race/ethnicity. Crit Rev Oncol Hematol. 2010;76(1):44-52.
14. Carey LA, Perou CM, Livasy CA, Dressler LG, Cowan D, Conway K, Karaca G, et al. Race, breast cancer subtypes, and survival in the Carolina Breast Cancer Study. JAMA. 2006;295(21):2492-2502.

15. Bauer KR, Brown M, Cress RD, Parise CA, Caggiano V. Descriptive analysis of estrogen receptor (ER)-negative, progesterone receptor (PR)-negative, and HER2-negative invasive breast cancer, the so-called triple-negative phenotype: a population-based study from the California cancer Registry. Cancer. 2007;109(9):1721-1728.

16. Cakir A, Gonul, II, Uluoglu O. A comprehensive morphological study for basal-like breast carcinomas with comparison to nonbasal-like carcinomas. Diagn Pathol. 2012;7:145.

17. Barnard ME, Boeke CE, Tamimi RM. Established breast cancer risk factors and risk of intrinsic tumor subtypes. Biochim Biophys Acta. 2015;1856(1):73-85.

18. Yang XR, Chang-Claude J, Goode EL, Couch FJ, Nevanlinna $\mathrm{H}$, Milne RL, Gaudet M, et al. Associations of breast cancer risk factors with tumor subtypes: a pooled analysis from the Breast Cancer Association Consortium studies. J Natl Cancer Inst. 2011;103(3):250-263.

19. Vanidassane I, Gogia A, Kumar L. Contemporary hormonal contraceptives and breast cancer risk: What do we learn? Natl Med J India. 2018;31(3):156-157. 